\title{
Internal Quality Failures of Apparel Industry: A Case from Sri Lanka
}

\author{
Rasika Lekamge ${ }^{1}$, Nishani Ekanayake ${ }^{2 *}$ \\ ${ }^{1}$ Faculty of Management and Finance, University of Colombo, Colombo, Sri Lanka \\ ${ }^{2}$ Department of Finance, Faculty of Management and Finance, University of Colombo, Colombo, Sri Lanka \\ Email: *nishanie@dfn.cmb.ac.lk
}

How to cite this paper: Lekamge, R., \& Ekanayake, N. (2021). Internal Quality Failures of Apparel Industry: A Case from Sri Lanka. Open Journal of Business and Management, 9, 2389-2406.

https://doi.org/10.4236/ojbm.2021.95129

Received: July 3, 2021

Accepted: September 14, 2021

Published: September 17, 2021

Copyright (c) 2021 by author(s) and Scientific Research Publishing Inc. This work is licensed under the Creative Commons Attribution International License (CC BY 4.0).

http://creativecommons.org/licenses/by/4.0/

\begin{abstract}
Apparel industry in Sri Lanka has recorded a consistent development advancing from the customary low-wage driven model into mind bogging worldwide recognized apparel hub in South Asia. Since quality holds a significant importance in the garment exports of developing countries, this research is a case based qualitative investigation to explore factors leading to quality failures in a medium-scale export oriented apparel manufacturing company located in the Colombo district of Sri Lanka. The study has employed thematic analysis to explore and analyze the inner experience of participants with regards to the quality aspects of garment manufacturing. Semi-structured interviews were used to collect data from ten employees through purposive sampling whom are directly responsible in the product line operations and for quality inspections. Findings suggest that the quality assurance, quality control and the operators' skill levels are vital in minimizing the quality failures in the selected company. Beside these, workers' absenteeism, machine problems and less awareness on quality standards contribute to quality failures. The findings further elaborate that the semi-skilled or un-skilled operators contribute to the internal quality failures of the selected apparel company. Findings of the study are beneficial to the practitioners of the apparel industry to enhance their understanding on factors which contribute to quality failures and would offer new insights on how to cater the customers with high quality apparel products.
\end{abstract}

\section{Keywords}

Apparel Industry, Quality Failures, Thematic Analysis, Sri Lanka

\section{Introduction}

Apparel industry is one of the key export sectors in Sri Lanka with a consistent 
growth from the customary low-wage driven model into mind bogging worldwide recognized apparel hub in the South Asian region. Sri Lanka's total export earnings for 2019 were $\$ 11.9$ billion, out of which $\$ 5.7$ billion was generated from apparel exports. Around 300 garment factories are operating in the country where over one million people are occupied in apparel related industries through direct and indirect employment (DailyFT, 2020). However, in the recent years, quality failure rate is growing in the apparel manufacturing industry of the country. The textile and apparel industry of Sri Lanka has gained a reputation among buyers over the years for quality, on-time deliveries and customer service. Comparing with other South Asian countries, India and Bangladesh, although their manufacturing and labor cost is lesser than Sri Lanka, still the country has gained its competitive position by maintaining the quality standards to an international level (Chelina Capital Corporation, 2013). Therefore, quality of the textile and apparel industry is vital for Sri Lanka to be an international leader in this sector.

Even though quality management has been extensively researched within developed nations (Oke \& Owaba, 2006; Mendes, Carlos, \& Lourenco, 2014), less attention was given to this labor-intensive manufacturing companies in developing nations (Belay, Kasie, Helo, Takala, \& Powell, 2014). Given this crucial role played by the quality factor in the garment supply chain as a global business, this paper contributes to the existing literature in apparel sector quality factor taking Sri Lanka as an illustrative example of a developing country. The study aims for a qualitative investigation to explore the phenomenon of quality failures in a selected apparel manufacturing company as a case study. The selected apparel firm is a well-established, export-oriented apparel manufacturing company which has encountered considerable issues in maintaining the quality of their apparel products in recent past. Findings of the research give useful insights to the academics, practitioners and to the top management of ABC Apparel Ltd. to implement effective strategies in order to reduce the future quality failures of their apparel products. This paper offers useful insights to the practitioners of the apparel industry to enhance their understanding on factors which contribute to quality failures and would give new insights to cater the customers with value added products in the industry. This study is a qualitative inquiry based on ten semi-structured face-to-face interviews with employees of the selected organisation. Due to the accessibility issue presented by the Covid-19 pandemic, the study sample is limited to one out of six factories in the chain of $A B C$ apparel Ltd. A larger sample size covering a considerable number of different factories could have resulted in more insights on quality failures and strategies to remediate them, which could improve the understanding of the quality aspects.

The remainder of this paper is organised as follows: Section two provides a review of prior literature covering the main focus of the study, quality assurance and quality aspect. The section also includes a brief introduction of the apparel sector in Sri Lanka. Section three introduces the apparel firm of this case: ABC 
apparel limited and the research problem under investigation. Section four discusses the sampling procedure and data collection of the study while the section five presents findings of the study with the generated thematic map. Section six presents the conclusions of the study with useful insights for practitioners.

\section{Literature Review}

Quality plays a vital role in the larger-scale production of consumer goods (Brun \& Moretto, 2014). Quality in the manufacturing context is commonly seen as free from defects and significant variation by adhering to certain standards (Benavides \& Landeghem, 2015). Quality remains a critical factor in manufacturing due to competitiveness (Anuar \& Mohd Yusuff, 2011). Gryna, Chua and Defeo (2007) emphasis the need of "world class" quality levels to satisfy today's market need as products and processes are becoming more complex in nature. Quality is an indispensable aspect especially in the garment industry which would impact to many performance indicators of a company. The most well-known practices and instruments used in the apparel industry to ensure quality of its products are: six sigma, disappointment mode and impact investigation (FMEA), quality capacity arrangement (QFD), benchmarking, 5S, total quality management (TQM), Pareto outline, Ishikawa, histogram and control graphs. Garment manufacturing as a labour-intensive industry is relied upon the human skills and capabilities to a greater extent. As mentioned by Jin (2004), nature and complexities of garment production make it difficult to completely implement a labour-saving technology. Since quality holds a significant importance in the global trade of garment exports, it is a vital determinant of success (Wang, 2013). Most of the international firms are involved in off-shore production whereby the production of the garments is located in specific developing countries for their cheap labour and operational costs (Chaudhry \& Hodge, 2012; Yu \& Lindsay, 2011). Yu and Lindsay have found that mis-communication between buyers and manufacturers due to different cultural and languages can affect the garment supply chain in the aspect of quality.

Variation also plays a role in garments' product quality which exists particularly when dealing with bulk production (Kadolph, 2007). Because of this, human errors could be occurring repeatedly from operators that are handling different materials or machines which need a regular and consistent monitoring (Glock \& Kunz, 2005). The processes of bundling, sewing and trimming operations added difficulty to the manufacturing process (Bubonia, 2012). Gunesoglu and Meric (2007) stated that the properties of fabrics and human emotion are those factors that will affect the daily operations of garment production. Therefore, quality inspectors are trained to be responsible for checking and monitoring the quality of garment parts and finished garments.

\subsection{Quality Assurance}

Literature suggests two important areas of concern with regard to the quality, 
especially in manufacturing organizations; quality assurance and quality control. Research has found that most manufacturing companies are stagnant at quality control (QC) and Quality Assurance (QA) stages of quality management implementations (Kemenade, 2014; Yusof, 2015). QA is defined as a part of quality management focused on providing confidence that quality requirement will be fulfilled (BS EN ISO 9000:2005). It is vital to plan and prevent problems from occurring at source which would otherwise lead a lasting bad impression of the brand (Dale, Van der Weile, \& Van Iwaarden, 2007). Thus, the shift from mere detection of problems toward prevention of non-conformance is essential. QA from the perspective of Dale et al. (2007) is based on the activities of; Training, Critical problem-solving tasks, Improving the design of the product, Improving process and services, Improving control over the process, Involving and motivating people.

As to Kadolph (2007) QA is the process of designing, producing, evaluating and assessing products to determine that they meet the desired quality level for the company's target market. Glock and Kunz (2005) use the term QA to portray the initiative of quality done by a company in order to implement the quality-oriented process in three stages of the product cycle; pre-production, during production and post-production. They stated that the process of QA involves activities in the product development, laboratory testing, inspection, statistical quality control, acceptance sampling, quality audits and analysis of returning merchandise. Towers \& Mc Loughlin (2005) describe both QA and TQM activities as focusing on a proactive approach of prevention rather than a reactive approach based on the detection of non-conforming product. By implementing a QA system and TQM, the process performance is monitored, issues are investigated, and sustainable improvements are suggested.

\subsection{Quality Control}

QC is another significant component in the quality process of manufacturing companies. Manufactures still equate QM with QC, hence it is widely referred and used in the manufacturing industry. QC is defined as part of quality management focused on fulfilling quality requirement (BS EN ISO 9000:2005). Gryna et al. (2007: p. 171) refers to QC as the process employed to meet standards consistently. Meanwhile, Dale et al. (2007) view QC as an important measure to greater process control and a lower incidence of non-conformance.

Although the garment companies successfully obtained the ISO accreditation and complied with the requirements of the international standards, the "reactive approach" of inspection and quality control are still widely used instead of "proactive approach" (Towers \& Mc Loughlin, 2005). As mentioned by Anuar and Mohd Yusuff (2011) the reliance on QC for quality is mainly to assure confirmation to customer requirements. The existence of the QC department in the garment industry is well known for the purpose of internal quality monitoring, examination and measurement of garments through a series of inspections. It 
covers different stages in the manufacturing process with a given specification and standard as agreed between retail buyers and manufacturers (Chen \& Jin, 2005). Although QC is often regarded as a traditional quality approach in the manufacturing sector through different methods of inspection (Glock \& Kunz, 2005; Burns, Mullet, \& Bryant, 2007) the process is still considered important in the garment industry (Rahman, 2010). Both domestic and overseas production utilise QC activities to meet the equality standards. Nonetheless, lack of geographic proximity has rendered difficulties to monitor QC in the overseas production, especially in the outsourced companies (Yu \& Lindsay, 2011; Goto \& Endo, 2014).

Most of the previous research conducted in the quality aspect of the apparel sector is overly concentrated on examining the adoption of total quality management (TQM) concept (Abeykoon \& De Alwis, 2015; Abdullah, 2007; Dassanayake, 2014). Considering the competitive nature of the industry, many other scholars extensively explored on the factors behind the success of export competitiveness of apparel companies (Rathnayake, Malsha, Dissanayake, \& Gunathilaka, 2020). Previous studies have predominantly utilised quantitative data analysis methods, which did not offer an in depth insights on quality failures. Based on the literature review a gap is evident on identifying factors for quality failures in the apparel products of the sector. Besides, there is a lack of literature conducted in the apparel sector of the Sri Lankan context. Therefore, this qualitative investigation is one of the first attempts to identify factors contribute to quality failures in apparel manufacturing sector of Sri Lanka as an illustrative study of the developing country context with a view to improve the competitive position of the apparel industry of Sri Lanka globally.

\subsection{Apparel Sector in Sri Lanka}

Sri Lanka is an emerging economy in South Asia, recently graduated to an upper middle-income country with a GDP per capita of USD 4,102 and a population of 22 million people. The country has achieved a remarkable economic growth after the ending of 30 years terrorist war in 2009, with an impressive average GDP annual growth of 5.6 percent during 2010 to 2018 (World Bank, 2019). Traditionally been an agro-based economy, with the introduction of open economy in 1977 the impact of industrial sector has increased over the impact of agricultural sector to GDP of the country (Lakshman \& Tisdell, 2000). The data retrieved from 2019 annual report of Central Bank of Sri Lanka (CBSL) shows the sectorial composition in the GDP as depicted in Figure 1.

As to Figure 1, the service sector records the highest contribution to the GDP by 58 percent while agricultural sector records the lowest contribution of 7 percent. Industrial sector contributed 32 percent to the GDP which as the second largest sector contribution to the national economy. The industrial sector recorded a growth of 2.7 percent in 2019 compared to 2018. Even though this expansion was supported by the positive contribution from all major sub sectors, the share coming from manufacturing activities where the apparel sector included 


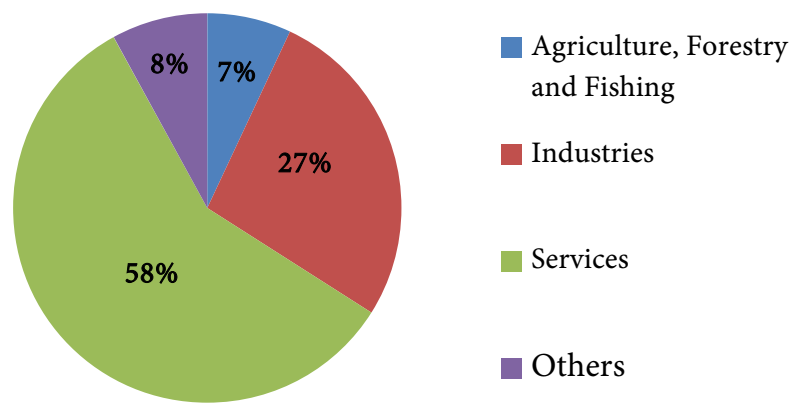

Figure 1. Sectorial composition in gross domestic product of Sri Lanka.

contributed with a slower growth of 1.9 percent compared to its growth of 3.6 percent recorded in 2018. This limited growth witnessed in the manufacturing sector, which accounts for 60 percent of the total industry sector is due to the many challenges the country had to face in recent years such as; Easter Sunday attacks, volatile oil prices and unfavorable weather conditions (CBSL, 2019). Textile, wearing apparel and leather related products which is one of the largest sub-activities related to manufacturing has therefore witnessed a contraction in the recent years in terms of the growth. This slower paced growth in the apparel export is depicted in Figure 2 from year 2013 to 2020 (CBSL, 2020).

The textiles and wearing apparel segment utilizes about 15 percent of the nation's workforce, and Sri Lanka records the most elevated clothing sends out per capita of any trading country in the region (BOI, 2020). According to Export Development Board (2015), earnings from exports of textile and apparel are accounted for 43 percent of total exports earnings of the country. As to Abeysinghe (2014), apparel accounts for nearly 70 percent industrial exports in Sri Lanka. The apparel industry in Sri Lanka is known as the "hub of South Asian fashion' and accounts for 17 percent of the market share of the US apparel imports (Industry capability report, 2019). Therefore, there is a more impact of apparel industry than other industries to the total export earnings of the country.

\section{Introduction to ABC Apparel Manufacturing Limited}

This study is an investigation of quality failure issue which exists at the $A B C$ Apparel Ltd located in Colombo, Sri Lanka. ABC Apparel Ltd was established in 2002, as a manufacturer and exporter of intimate apparels and garments, which exports 99 percent of its production to the parent company in Italy. The parent company bi-annually measure the performances of ABC Apparel Ltd based on the key performance indicators of the industry such as; total minutes produced, cost per minute, efficiency level of the production, etc. During its 17 years of operation in Sri Lanka, ABC Manufacturing Ltd have expanded its business gradually and now employed a work force of over 2200 employees. At the recently concluded Presidential Export Award conducted by the Sri Lanka Export Development Board, ABC Apparel Ltd has received a merit award for the Apparel 


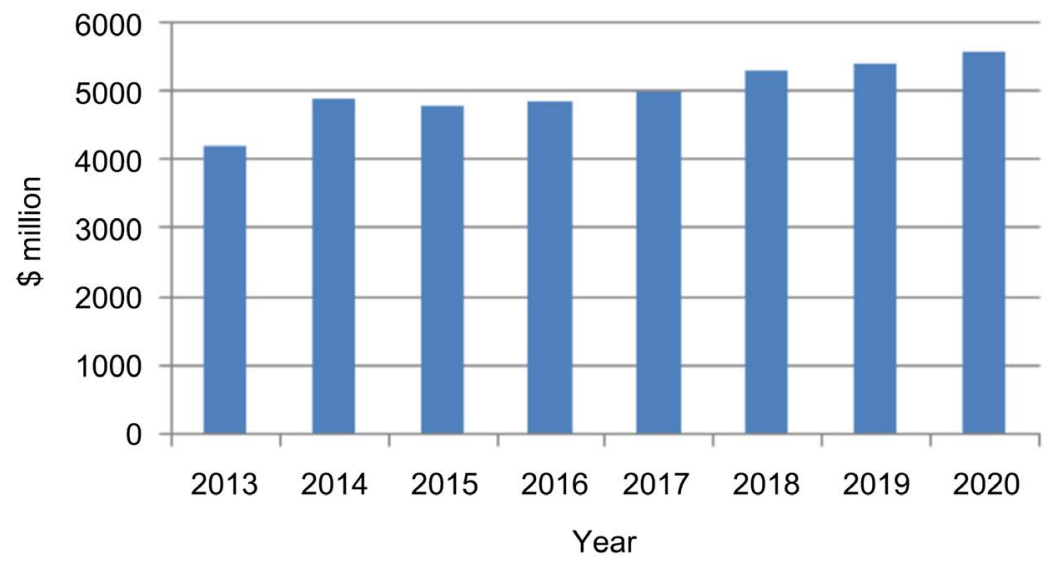

Figure 2. Apparel exports of Sri Lanka from 2013 to 2020.

sector. Also the company won three awards from Best Corporate Citizen Award ceremony for its continuing performance in the apparel industry in 2019. In future years the company aims to achieve a sustainable growth in the apparel industry while ensuring high standard of quality and consistency across all of its products lines.

\section{Problem Statement}

As an export-level clothing fabricating organization, achieving Acceptable Quality Level (AQL) is vital for the commercial success of ABC Apparel Ltd. Product disappointments of the customers are feared by the producers of textile and apparel industry which possibly cause reputational damage beside the financial loss to the company by losing customers. With the worldwide rivalry, clothing fabricates bring to the table extraordinary quality items to attract the best clients. Quality is therefore essential in the clothing industry and is regarded as a key performance indicator.

However, in recent years $\mathrm{ABC}$ Apparel Ltd has witnessed moderate level of surge in the product line quality failures of their fabric items. Compared to January, the AQL fail rate increased by more than 60 percent in December 2019. These inner quality disappointments have also impacted to a few KPI's of the company. Due to the increased fault products the company had faced with sewing revamp, left over clothing piles, texture dismissals and loss in the air shipments due to value failures. AQL group pass rate is a significant marker for performance of the inward quality of the garment products. Figure 3 signifies the quality issue the company is facing due to increased batch fail rate in the year 2019.

This issue, pertaining to the increased quality failures at ABC Apparel Ltd therefore needs attention. This study is an attempt to investigate the reasons for such quality failures with an aim to recommend the best strategies for the company to improve the quality of its product and to gain is strategic position in the textile market. Findings of the study on quality failures based on ABC Apparel 


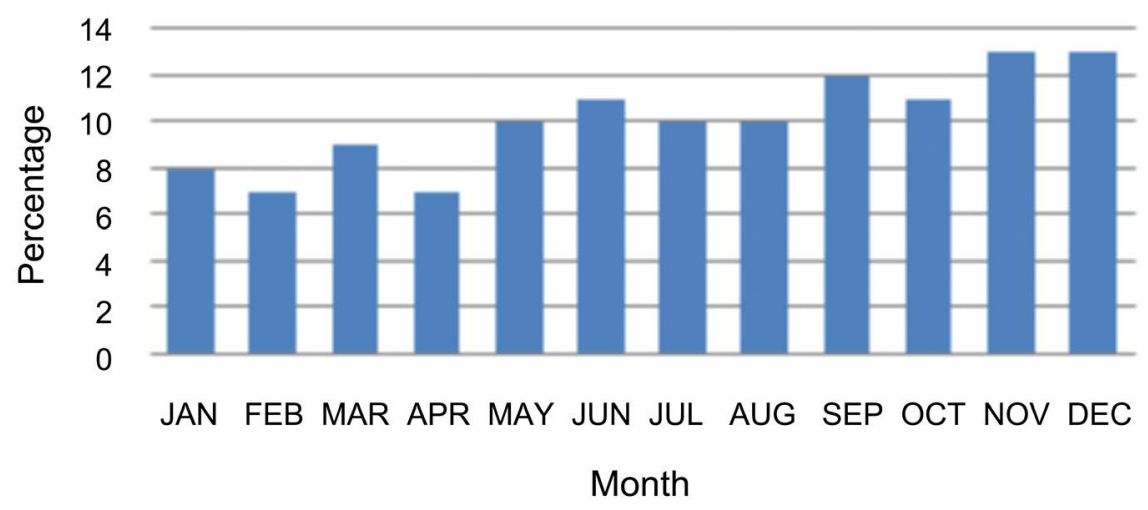

Figure 3. Monthly AQL batch fail rate in 2019.

Ltd offers a better understanding of the quality aspect in similar organisations and therefore can suggest recommendations to improve the quality standards of the local apparel industry.

\section{Research Methodology}

This research has chosen qualitative design due to the nature of the research problem. As this study attempts to understand the reasons for quality failures through participants' interpretations, it needs to go into the field to find out lived experiences in the given local specificities. Textile and apparel industry is predominantly labor-intensive industry in the medium-scale manufacturing institutions in Sri Lanka. Selecting a qualitative design therefore helps to take a holistic and a comprehensive view by exploring the inner experiences of participants (Creswell, 2013). The study has employed thematic analysis which facilitates the search for patterns of experience within a qualitative data analysis. As this study opt for interpretive data analysis to "search for patterns of experience" by investigating mainly human factors which affect to the quality failures, thematic analysis considered as the best-suited data processing method for the study. Guest, Mac Queen and Namey (2011) described thematic analysis as the most widespread form of qualitative research analysis due to its useful ability to capture the complexities of meaning within a set of data.

\subsection{Sampling Procedure}

The researcher has employed purposive sampling technique, which is a method of non-probability sampling in this research study. As Maxwell (2004) this is a strategy where specific events, people or situations is chosen will fully to get vital information that can't be acquired from other means. Therefore, as mentioned above a handpicked number of participants in production and monitoring process of $\mathrm{ABC}$ apparel manufacturing Ltd have been selected in order to keep in line with the theme of the study. Accordingly ten participants were approached in the production, quality control and quality audit departments of the company. These interview participants are directly responsible for quality of fi- 
nished products. All the interviews were conducted in the premises of ABC Apparel Ltd and recorded with the consent of participants.

\subsection{Data Collection}

Depending on the research problem, context and the ease of accessibility, this applied research has employed semi-structured interviews to collect data from the selected 10 participants. Semi-structured interviews are congruent with the thematic analysis which is concurrently occurring with the data collection. The interview guide was constructed by referring to the interview guide used by $\mathrm{Yu}$ sof (2015) in his analysis of human-focused quality management framework on the performance of garment industry of Malaysian context. This interview guide was considered as applicable in the current applied research due to the similarities of the two studies in terms of the context; developing countries and the industry; garment industry. The 15 interview questions were groups under three themes; quality assurance (QA), quality control (QC) and general questions as informed by the literature and the general understanding of the researcher who works in the $\mathrm{ABC}$ apparel Ltd. Interview statements/questions which represent these three themes are illustrated in Table 1.

Data coding was conducted manually using the features of MS words and MS

Table 1. Interview statements used in the semi-structured interviews.

\begin{tabular}{|c|c|}
\hline Themes & Interview questions \\
\hline \multirow{5}{*}{$\begin{array}{l}\text { Quality } \\
\text { Assurance (QA) }\end{array}$} & $\begin{array}{l}\text { Explain briefly the flow of garment manufacturing in this company with a } \\
\text { special focus to quality assurance of the end product. }\end{array}$ \\
\hline & $\begin{array}{l}\text { Explain briefly the inspection procedure of the product line that you are } \\
\text { responsible. }\end{array}$ \\
\hline & Do you consider implementation of quality assurance is challenging in your \\
\hline & product line. Give reasons to your answer. \\
\hline & What role played by the documentation and records in quality assurance? \\
\hline \multirow{6}{*}{$\begin{array}{l}\text { Quality Control } \\
\text { (QC) }\end{array}$} & $\begin{array}{l}\text { Briefly explain the procedure for quality control/ inspection in the product line } \\
\text { which you are responsible for. }\end{array}$ \\
\hline & What is the common problem in clothing production? \\
\hline & Is there any problem faced by you with regard to quality control? Explain. \\
\hline & Is there any key performance indicator (KPI) or target to be achieved in the \\
\hline & production and quality control of what you are responsible for? Explain. \\
\hline & How do you handle customer complaints? \\
\hline \multirow{6}{*}{$\begin{array}{c}\text { General } \\
\text { Questions }\end{array}$} & $\begin{array}{l}\text { Do you think your routine tasks and working hours impact to the quality of the } \\
\text { garment? Explain. }\end{array}$ \\
\hline & $\begin{array}{l}\text { Are you confident that you had enough training in your job to achieve better } \\
\text { quality of the garment? Explain. }\end{array}$ \\
\hline & What are the common defects you found in the sewing assembly line? \\
\hline & What are the main challenges you meet in the quality inspection process? \\
\hline & $\begin{array}{l}\text { How frequent the major defects were found during the final inspection? In } \\
\text { which areas you have found major defects? }\end{array}$ \\
\hline & $\begin{array}{l}\text { How would you recommend to improve the quality of garments in your } \\
\text { company? }\end{array}$ \\
\hline
\end{tabular}

Source: Researchers' (2020). 
Excel. Emerging concepts were identified through line-by-line coding in a typed interview transcript using MS words. Later the generated codings were transferred into an MS Excel document for conceptual categorisation and to identify emerging themes. A colour code was used to differentiate the concepts generated from each interview. The generated, concepts were grouped under conceptual labels which facilitated the emergence of themes. This evolving analysis and coding process was saved in different revised versions of MS Excel documents. These documents were kept safe with easy access and were often referred when required for further comparisons and revisions in the development of themes.

\section{Data Analysis and Findings}

\subsection{Descriptive Statistics of the Sample}

The descriptive statistics with regard to the sample participants is presented in Table 2. The research participants are directly responsible for the maintenance of the internal quality of the considered company.

The participants of this study comprised of 90 percent females and 10 percent males. Amongst the respondents, 50 percent were staff officers, 40 percent executives and 10 percent managers. 50 percent of these respondents were aged between 41 to 50, 40 percent between 31 and 40, and a 10 percent of them between 18 to 25 age group. Respondents educational levels varied only in the capacity of GCE AL and postgraduate diploma. Majority of the sample, that is 60 percent held post graduate level of educational qualifications. Nobody possessed more than 20 years of experience, yet 60 percent has experience between 15 to 20

Table 2. Descriptive statistics of the sample.

\begin{tabular}{|c|c|c|c|}
\hline \multicolumn{2}{|c|}{ Characteristics } & \multirow{2}{*}{$\begin{array}{c}\text { Frequency } \\
1\end{array}$} & \multirow{2}{*}{$\begin{array}{c}\text { Percentage } \\
10 \%\end{array}$} \\
\hline & Male & & \\
\hline Gender & Female & 9 & $90 \%$ \\
\hline \multirow{3}{*}{ Position } & Executives - Production & 4 & $40 \%$ \\
\hline & Staff officers - Production & 5 & $50 \%$ \\
\hline & Manger - Operations & 1 & $10 \%$ \\
\hline \multirow{2}{*}{ Education level } & G.C.E A/L & 4 & $40 \%$ \\
\hline & Postgraduate Diploma & 6 & $60 \%$ \\
\hline \multirow{3}{*}{ Age } & $18-25$ years & 1 & $10 \%$ \\
\hline & $31-40$ years & 4 & $40 \%$ \\
\hline & $41-50$ years & 5 & $50 \%$ \\
\hline \multirow{4}{*}{ Experience } & less than 5 & 1 & $10 \%$ \\
\hline & 5 but less than 10 & 1 & $10 \%$ \\
\hline & 10 but less than 15 & 2 & $20 \%$ \\
\hline & 15 but less than 20 & 6 & $60 \%$ \\
\hline \multirow{3}{*}{ No. of subordinates } & 1 to 5 & 1 & $10 \%$ \\
\hline & 6 to 10 & 4 & $40 \%$ \\
\hline & More than 15 & 5 & $50 \%$ \\
\hline
\end{tabular}

Source: Field data. 
years of service. 20 percent of respondents had experience between 10 to 15 years, while equal percentage of 10 percent having less than five or between 5 to 10 years of experience. 50 percent of them had more than 15 subordinates while 40 percent of them managed 6 to 10. Least of the respondents that is 10 percent had less than 6 subordinates.

\subsection{Core Themes}

The collected data was analyzed using six-phase thematic analysis approach. In the initial phase to become familiar with data, the researcher listened to the recorded interviews over and over in the transcription process. Through the literature survey the researcher had anticipated start codes which made the interview guide statements to break into three themes as explained earlier. However, these were reviewed during the analysis procedure through careful reviewing. In the second phase, the researcher generated an initial list of variables that had a re-occurring pattern in the data related to the research question. The researcher had to go back and forth if the initially generated list in searching for themes which is the second phase of data analysis in thematic analysis. Saldaña (2009) experienced that the coding process of the thematic analysis is rarely completed the first time. Each time, researchers should strive to refine codes by adding, subtracting, combining or splitting variables into potential categories and subcategories. Guest et al. (2011) mentioned that this important initial coding phase created the foundation for further detailed analysis and enabled the reorganization of data as themes emerged. Using MS words and MS Exel applications, the researcher manually searched and found emerging themes which are repeatedly seen in the ten participant interview transcripts. On completion of this manual filtering step, a reduced set of 15 variables remained, any of which had been repeated ten or more times per participant. Variables with a counted frequency fewer than ten were deemed less significant and not included in further analysis. Marshall (1998) observed the need to simplify or reduce the number of variables in the initial raw data set to a critical, minimum set of variables in the thematic analysis.

Building on previous analysis work that enabled the emergence of 15 overarching groups of ideas and the development of candidate themes, the fourth phase involved the refining and reworking of proposed themes and required expanded searches for data that supported or refuted the candidate themes (Guest et al., 2011). At the fourth stage clear and coherent patters within the candidate themes were observed. To improve the validity of each theme, the researcher conceptually connected the emerging themes to the research question. This step was important as if offered clarity in the way the current themes related back to the original data set. In the fifth step; defining and naming themes, the researcher considered the essences of each theme and how they relate to the whole picture of the data. Names were identifies to illustrate the full sense of the theme. In this stage, the researcher referred to the literature to name the themes in a logi- 
cal, definable and a separable way from each other. The five themes that emerged in the final stage of data analysis are; Quality assurance, Quality control, Skill level of operators, Absenteeism and Machine failure. Using these five themes, the researcher created the thematic map with casual relationships of each theme as depicted in Figure 4.

Each of the identified sub-themes with the narratives of participants is discussed in the next part with the aim of identifying the nature of quality failures in ABC Apparel Ltd.

\subsubsection{Quality Assurance}

QA is defined as a part of quality management focused on providing confidence that quality requirement will be fulfilled (BS EN ISO 9000:2005). It is vital to plan and prevent problems from occurring at source which would otherwise lead a lasting bad impression of the brand (Dale et al., 2007). Nine out of ten respondents were aware and believed that the raw material quality assurance practices are vital in making a quality product. In this regards, a quality section auditor opined that "When the fabric is brought to our stores, we conduct an inspection of the material". Another participant added "in this company our quality assurance procedures start from the stores, inspection area, inspection of the received fabric bales".

In the cutting room quality assurance procedures, only seven respondents commented on the quality assurance procedures. A cutting officer stated that "the workers cut the materials only after confirming the accuracy of pattern boards". Another respondent; "in the cutting section after laying the fabric an inspection will be carried out prior to the cutting". Three participants were in the same view of "from receiving the fabric to the cutting section, random inspection happens before cutting begins". In the production section of ABC apparel manufacturing company, all the respondents stated that there are some quality assurance procedures to be followed. An officer in the production department mentioned that "each operator is responsible for checking every part before starting the sewing, with patterns". Another participant opined "usually when a cut panel reaches to the module, first we have to check the items with

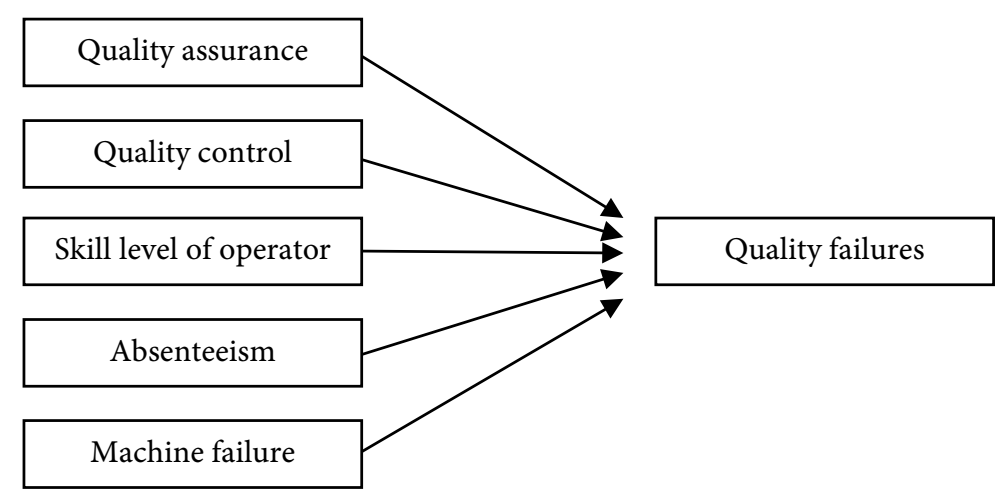

Figure 4. Thematic map with core themes. 
pattern boards", while another mentioned "before starting the production we are stitching a sample in sample room and identify all the important quality points". All the participants are aware what documents and records they should refer in the process of quality assurance. A technical officer stated "we follow failure reports to check what kind of defects were reported during early production stages and from that we can have a better idea before starting the new style of production". Another emphasized that "I strongly believe these records are very important for quality assurance".

\subsubsection{Quality Control}

Majority of the respondents were aware of the quality control practices and there usage level in $\mathrm{ABC}$ Apparel manufacturing company. A staff officer in the production department stated "in the cutting room, two auditors are kept to make sure the quality of cut panels". Another participant was in the same view that "after cutting a layer, again we carry out an inspection before the cut panel was send to production module". Officer in the quality control has the same viewpoint and mentioned; "random inspections are going on with fabric laying and after cutting". Regarding quality control process in the production line of the ABC Apparel manufacturing company, all the respondents had adequate knowledge on quality control. Quality control officer in the production department stated that "during production, most important thing we adhere to is instructing the operator to check the fourth piece". Another participant supported this emerged theme stating; "during production, our rule is that after every five pieces, one-piece need to check by the operator". The participants agreed that there is one operator who is responsible for checking the finish garments in the module. "This is the way we are controlling quality" mentioned the auditor in charge for the quality. A technical officer articulated in a different way stating that; "at the final check, operator must ensure whether the garment is being sewn according to the original sample, whether the required specifications are being followed".

\subsubsection{Operator Skill Level}

Operator skill level has a significant influence over the quality factor of the garment products of the apparel company. An interviewee who is a production manager stated that "the most common problem with regards to quality control is the lack of knowledge of the operators". Another participant also stated that "major problem we face is newly appointed unskilled machine operators". Another officer had the same viewpoint and stated as "specially machine operators knowledge level is not the same". A team officer in the production department opined that "major common problem we face is the weak knowledge of newly appointed unskilled machine operators". Another staff officer in the quality control department stated that "when we are explaining something, some operators do not understand or they understand with a variation". Same view is given by another participant as "when we are operating a line, we find that each 
operator's knowledge and grasping powers are different".

\subsubsection{Absenteeism}

Respondent views supported in the emergence of this theme; absenteeism. A participant, manager of the production department stated that "one of the most common problems in my section is operator absenteeism and high turnover". With this regards another participant stated that; "absenteeism and turnover has a huge impact to the quality of garment manufacturing garment". Audit leader also opined that; "absenteeism is one of the major factors effecting to the quality failures". Arguing from a different view point another participant stated; "when an operator is absent, her work is replaced by another operator, but in order to get the replaced operator up to the required standard is a considerably difficult and time consuming task for us". A staff officer in the quality control department stated that "absenteeism and turnover are the major issues. Because of these two reasons we have to put less skilled operators in the process and they are contributing to a more damage to the quality aspect".

\subsubsection{Machine Failures}

This theme was emerged in the data analysis as a significant contributor to quality failures of the considered company. Correct machine set up is vital component to address in order to prevent defects in the manufactured garments. Many participants vouched on the need to have smooth functioning machines with a proper set up to the fabric type use in the manufacturing process. In this regard the production manager stated; "a major problem we are facing is the machine problem. Whatever the new machine we use, if they are not correctly set up, it blocks us in getting a quality product". A staff officer in the quality control department also stated that; "a machine which was not accurately set up makes more damages to the final quality and we experience this". He further mentioned that "most of the time sewing machines are not correctly setup which makes big issues to the operator". Another participant agreed on the emergence of this theme stating that "even a skill operator cannot do a perfect job with a machine of a poor condition".

According to the patterns of responses it is apparent that quality assurance, quality control, operator skill level, absenteeism and machine failures play a vital role in reducing the quality failures in $\mathrm{ABC}$ Apparel manufacturing company. The findings further elaborate that the semi-skilled or unskilled operators contribute to the internal quality failures. Furthermore, majority of respondent stated that their common problem in garment manufacturing is absenteeism and turnover.

\section{Conclusion}

Apparel industry at present is becoming highly competitive and challenging due to the increased number of competitors, short product life cycle, higher quality expectations of the customers and the downturn of global economy as a conse- 
quence of the global pandemic situation. Therefore, the manufacturers of apparel are seeking means of bringing down the manufacturing cost yet without compromising the quality. From the evidence found in this study, the cost of repair incurred due to defective products involving rework contributes considerably towards the manufacturing cost. This study, which has explored the contributing factors for quality failures in ABC Apparel Company, found that the skill level of the operators, workers' absenteeism, and machine failures are reasons for quality failures in apparel products. Further, findings highlight the important role played by quality control and quality assurance in the manufacturing process of the apparel products. Knowledge level and the grasping power were noticeably found as impacting the skill level of the operators. Higher level of absenteeism had caused unbearable workload due to the operator replacement to cover the operations of the other absentees. According to the respondents, incorrect setup of machines too had contributed to the quality failures resulting in a poor-quality garment product.

Findings of this research stress the importance of adopting quality assurance and quality control practices at ABC Apparel Ltd., which includes initial inspection of materials, inspection of fabric layers and patterns and identifying quality points using specifications prior to production. The researcher suggests that all responsible actors of the production process should possess a clear idea about the documents involved i.e. the operation description and measurement sheet. Necessary training should be provided to increase the awareness of these documents with the consent of the top-level managers. As gleaned from the findings, the operator's skill level is an indicator of his/her performance and the ability to handle the given type of machine. The skills need to be maintained by an operator should include number of sewing machine he/she can operate, production capacity per operation, sewing efficiency, servicing period in factory and seam quality. Researcher suggests that the training given to enhance the above capacities could lead to increased product quality. Replacement of an operation by semi-skilled or unskilled operator due to an absent operator greatly affects the quality. Researcher suggests that the introduction of skill based incentive schemes would motivate the operator to be present at work while encouraging unskilled or semi-skilled operators to enhance their skill levels. In this way, the ABC Apparel limited could further enhance and strengthen their market position in the industry while attracting more business opportunities in future.

\section{Conflicts of Interest}

The authors declare no conflicts of interest regarding the publication of this paper.

\section{References}

Abdullah, A. (2007). Study of Total Quality Management (TQM) Application by Malaysian Small and Medium-sized Manufacturing Enterprises (SMEs). PhD Thesis, Cardiff 
University. http://orca.cf.ac.uk/55700/

Abeykoon, M. W. B., \& De Alwis, C. (2015). The Impact of Total Quality Management Practices on Export Performance of Apparel Exporters in Sri Lanka. Kelaniya Journal of Human Resource Management, 10, 1-2. https://doi.org/10.4038/kjhrm.v10i1-2.23

Abeysinghe, B. (2014). The Time Has Come for Sri Lanka to Look Beyond Apparel EXports. Daily FT. http://www.ft.lk

Anuar, A., \& Mohd Yusuff, R. (2011). Manufacturing Best Practices in Malaysian Small and Medium Enterprises (SMEs). Benchmarking: An International Journal, 18, 324-341. https://doi.org/10.1108/14635771111137750

Belay, A. M., Kasie, F. M., Helo, P., Takala, J., \& Powel, D. J. (2014). Adoption of Quality Management Practices: An Investigation of its Relationship with Labor Productivity for Labor-Intensive Manufacturing Companies. Benchmarking: An International Journal, 21, 77-100. https://doi.org/10.1108/BIJ-02-2012-0011

Benavides, M. B., \& Landeghem, H. V. (2015). Implementation of S-DBR in Four Manufacturing SMEs: A Research Case Study. Production Planning and Control, 13, 225-236.

BOI (2020). Investment Guide. BOI Publications. https://investsrilanka.com/boi-publications/

Brun, A., \& Moretto, A. (2014). Organisation and Supply Chain for Quality Control in Luxury Companies. Journal of Fashion Marketing and Management, 18, 206-230. https://doi.org/10.1108/JFMM-11-2012-0070

Bubonia, J. E. (2012). Apparel Production Terms and Processes. Bloomsbury Publishing USA.

Burns, L. D., Mullet, K. K., \& Bryant, N. O. (2007). The Business of Fashion: Designing, Manufacturing, and Marketing. Bloomsbury Publishing USA.

CBSL (2019). Annual Report.

https://www.cbsl.gov.lk/en/publications/economic-and-financial-reports/annual-report s/annual-report-2019

CBSL (2020). Annual Report, Central Bank of Sri Lanka.

https://www.cbsl.gov.lk/en/publications/economic-and-financial-reports/annual-report s/annual-report-2020

Chaudhry, H., \& Hodge, G. (2012). Postponement and Supply Chain Structure: Cases from the Textile and Apparel Industry. Journal of Fashion Marketing and Management, 16, 64-80. https://doi.org/10.1108/13612021211203032

Chelina Capital Corporation (2013). Chelina Capital Corporation Information. https://rocketreach.co/chelina-capital-corporation-profile b5c89743f42e355a

Chen, Y., \& Jin, J. (2005). Quality-Reliability Chain Modeling for System-Reliability Analysis of Complex Manufacturing Processes. IEEE Transaction on Relaibility, 54, 475-488. https://doi.org/10.1109/TR.2005.853441

Creswell, J. (2013). Qualitative Inquiry and Research Design: Choosing Among Five Approaches (3rd ed.). Sage Publications. https://doi.org/10.1177/0011000006287390

DailyFT (2020). Apparel Industry Attracts over $\$ 500$ m Orders for PPEs. https://www.ft.lk/front-page/Apparel-industry-attracts-over-500-m-orders-for-PPEs/4 4-700572

Dale, B. G., Van der Weile, T., \& Van Iwaarden, J. (2007). Managing Quality. John Wiley \& Sons.

Dassanayake, H. C. (2014). An Investigation on Practicing Principles of Total Quality Management in Apparel Industry in Sri Lanka: With Reference to ISO 9000 Quality 
Management Principles. Reshaping Management and Economic Thinking through Integrating Eco-Friendly and Ethical Practices Proceedings of the 3rd International Conference on Management and Economics, University of Ruhuna.

Export Development Board (EDB). (2015). Performance of the Export Sector of Sri Lanka Report of Export Development Board. http://www.srilankabusiness.com/pdf/performance of exports 2014.pdf

Glock, R. E., \& Kunz, G. I. (2005). Apparel Manufacturing: Sewn Product Analysis (4th ed.). Prentice Hall.

Goto, K., \& Endo, T. (2014). Labor-Intensive Industries in Middle-Income Countries: Traps, Challenges, and the Local Garment Market in Thailand. Journal of the Asia Pacific Economy, 19, 369-386. https://doi.org/10.1080/13547860.2014.880283

Gryna, F. M., Chua, R. C. H., \& Defeo, J. A. (2007). Juran's Quality Planning and Analysis for Enterprise Quality (5th ed.). Tata McGraw-Hill Publishing Company Limited.

Guest, G., MacQueen, K., \& Namey, E. (2011). Applied Thematic Analysis. Sage Publications. https://doi.org/10.4135/9781483384436

Gunesoglu, S., \& Meric, B. (2007). The Analysis of Personal and Delay Allowances Using Work Sampling Technique in the Sewing Room of a Clothing Manufacturer. International Journal of Clothing Science and Technology, 19, 145-150. https://doi.org/10.1108/09556220710725739

Industry Capability Report (2019). Industry Capability Report: Sri Lanka Apparel Sector, Sri Lanka. Export Development Board.

Jin, B. (2004). Apparel Industry in East Asian Newly Industrialized Countries: Competitive Advantage, Challenge and Implications. Journal of Fashion Marketing and Management: An International Journal, 8, 230-244. https://doi.org/10.1108/13612020410537915

Kadolph, S. J. (2007). Quality Assurance for Textiles and Apparel. Fairchild Books.

Kemenade, E. V. (2014). Theory C: The Near Future of Quality Management. The TQM Journal, 26, 650-657. https://doi.org/10.1108/TQM-12-2013-0133

Lakshman, W. D., \& Tisdell, C. A. (2000). Sri Lanka’s Development since Independence: Socio-Economic Perspectives and Analysis. Nova Science Publishers.

Maxwell, J. A. (2004). Using Qualitative Methods for Causal Explanation. Field Methods, 16, 243-264. https://doi.org/10.1177/1525822X04266831

Mendes, L., Carlos, V., \& Lourenco, L. (2014). The Influence of TQM on Organizational Commitment, Organizational Citizenship Behaviours, and Individual Performance. Transylvanian Review of Administrative Sciences, 10, 111-130.

Oke, S. A., \& Owaba, O. E. C. (2006). Implementation of ISO-Based Quality Management Systems: A Review of the Literature. International Journal of Productivity and Quality Management, 2, 81-90. https://doi.org/10.1504/IJPQM.2007.011469

Rahman, M. M. (2010). Apparel Merchandising and Quality Control. VDM Verlag Dr. Müller.

Rathnayake, D., Malsha, H., Dissanayake, C., \& Gunathilaka, L. (2020). Factors behind the Success of International Competitiveness of Apparel Industry in Sri Lanka with Special Reference to Vertical Integration Strategy. 13th International Research Conference, General Sir John Kotelawala Defence University.

Saldaña, J. (2009). The Coding Manual for Qualitative Researchers. Sage Publications.

Towers, N., \& McLoughlin, J. (2005). Effective Total Quality Management in the Textile Fashion Retail Supply Chain: A Pilot Survey of the UK Textile Manufacturers. Journal 
of the Textile Institute, 96, 87-92. https://doi.org/10.1533/joti.2004.0058

Wang, X. (2013). The Determinants of Textile and Apparel Export Performance in Asian Countries. Digital Repository, Lowa State University.

https://lib.dr.iastate.edu/cgi/viewcontent.cgi?referer=https://www.google.com/\&httpsre dir $=1 \&$ article $=4649 \&$ context $=$ etd

World Bank (2019). Overview of Sri Lanka.

https://www.worldbank.org/en/country/srilanka/overview

Yu, Y., \& Lindsay, V. (2011). Operational Effects and Firms' Responses: Perspectives of New Zealand Apparel Firms on International Outsourcing. The International Journal of Logistics Management, 22, 306-323. https://doi.org/10.1108/09574091111181345

Yusof, N. J. M. (2015). Human-Focused Quality Management (HFQM) Framework towards Performance Excellence for Malaysian Ready-to-Wear Garment Industry. PhD Thesis, Manchester Metropolitan University. 